\title{
نحو سياسة عامة تحمي حقوق العاملين الفلسطينيين بأجر في "إسرائيل" والمستعمة تهمرات
}

\section{The Rights of Palestinian Workers in Israel and its Settlements: Towards a Protective Policy}

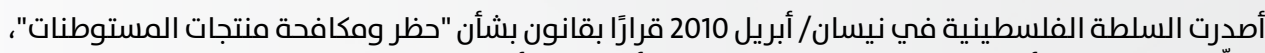

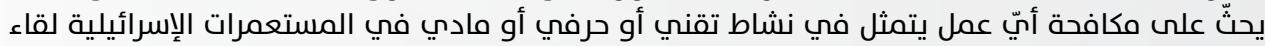

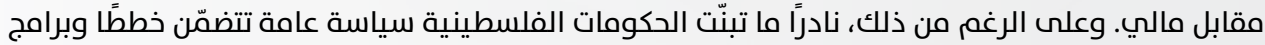

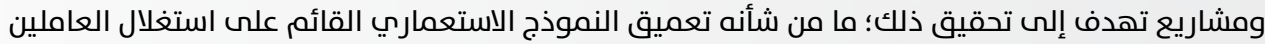
الفلسطينيين بأجر في "إسرائيل" والمستعمرات. ولذلك، تقترح هذه الدراسة سياسة عامة، همّها الرئيس

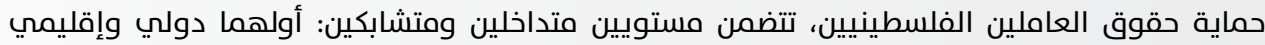

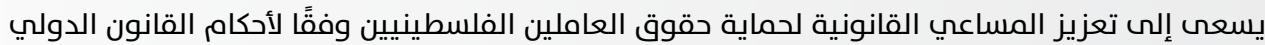

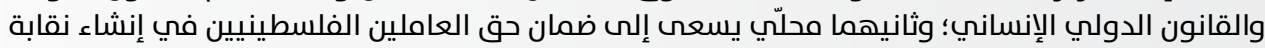
فلسطينية مستقلة تحمي حقوقهم الدون من الاستغلال الإسرائيلي.

كلمات مفتاحية: العمال الفلسطينيون، القانون الدولي،، "اسرائيل"، المستعمرات، حقوق العمال، انتهاكات "إسرائيل".

In April 2010, the Palestinian Authority passed a law aimed at banning goods produced in settlements and urging Palestinians not to work in the settlements or provide them with technical or material assistance. Despite this, Palestinian governments have seldom adopted a public policy that includes plans or programs to put an end to the practice of Palestinians working in the settlements, further entrenching a colonial model based on the exploitation of Palestinian workers in Israel and the settlements. This paper thus proposes a public policy that protects the rights of Palestinian workers. This policy is divided into two interconnected levels. The first level is international and regional and seeks to strengthen legal efforts to protect the rights of Palestinian workers in accordance with the provisions of international law and international humanitarian law. The second is local and seeks to ensure the right of Palestinian workers to establish an independent Palestinian labor union that protects workers from Israeli exploitation.

Keywords: Palestinian Workers, International Law, Israel, Settlements, Labor Rights, Israeli Violations. 


\section{مقدمة}

مثَّل تنامي تدفق حركة العاملين الفلسطينيين بأجر في "إسرائيل" والمستعمرات الإسرائيلية في الأراضي المحتلة عام 1967 1(،

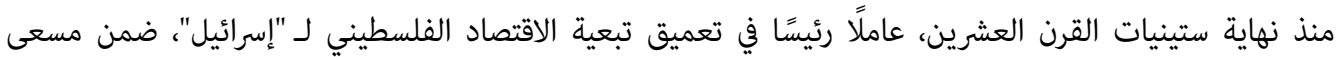
استعماري يحرص على السيطرة على عناصر الإنتاج الرئيسة، وبغرض إضعافه واستنزافه والتحكم فيه وإلحاقه قسرًا

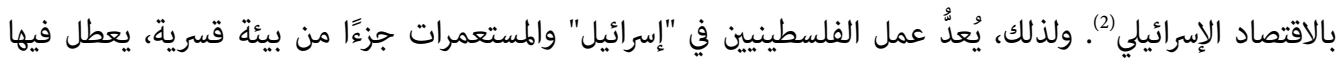
المستعمِر الإسرائيلي قدرةً الفلسطينيين على خلق اقتصاد مستقل قادر على خلق فرص عمل للباحثين عن عمل في الضفة الغربية وقطاع غزة، وذلك بفرضه مجموعة من القيود والشروط والإجراءات القسرية على العاملين الفلسطينيين (3). يُمارس المستعمِر الإسرائيلي، إضافة إلى ذلك، العديد من الانتهاكات في حق العاملين الفلسطينيين بأجر في "إسرائيل" والمستعمرات، كالتمييز العنصري وانعدام المساواة والإهانة والإذلال؛ إذ تتلقى العديد من المنظمات الإقليمية والدولية بلاغات عدة عن انتهاكات في حق العاملين الفلسطينيين، تُوصف بأنها نوع من العقاب الجماعي والاستغلال في طريق

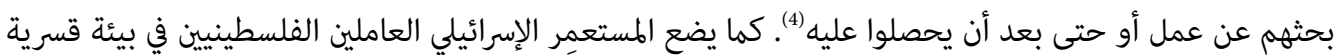
للعمل في مستعمرات، تُعدّ وفقًا لقرار مجلس الأمن التابع للأمم المتحدة 2334 (2016) غير قانونية وغير شرعية (5). يثّل العاملون الفلسطينيون بأجر في "إسرائيل" والطستعمرات نحو ثلث التوزيع النسبي للعاملين الفلسطينيين في الضفة الغربية وقطاع غزة لمن أعمارهم 15 سنة فأكثر (6)، وتُساهم دخولهم بنحو 14 في المئة من الدخل القومي الإجمالي الفلسطيني (7).

لكن ما يستوقفنا هنا هو أن تنامي تدفق حركة العاملين الفلسطينيين بأجر في "إسرائيل" والطستعمرات، المتزامنة مع تنامي الانتهاكات الإسرائيلية لليد العاملة الفلسطينية التي برزت مؤخرًا مع إلقاء الجيش الإسرائيلي للعاملين الفلسطينيين المشتبه بإصابتهم بفيروس كورونا المستجد (كوفيد-19) عند مداخل نقاط التفتيش بالضفة الغربية من

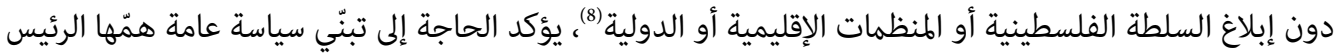
حماية حقوق العاملين الفلسطينيين ووقف استغلالهم.

1

الفلسطينية المحتلة منذ عام 1967.

2 Yusif A. Sayigh, "The Palestinian Economy under Occupation Dependency and Pauperization," Journal of Palestine Studies, vol. 15, no. 4 (Summer 1986), pp. 48-50.

3

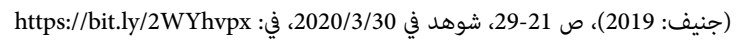

المرجع نفسه، ص 27

5 https://bit.ly/3dq0ISp 5

6 الجهاز المركزي للإحصاء الفلسطيني، مسح القوى العاملة الفلسطينية: التقرير السنوي 2019 (رام الله: 2020)، ص 92، شوهد في https://bit.ly/3lxG59R

7 الجهاز المركزي للإحصاء الفلسطيني، الحسابات القومية بالأسعار الجارية والثابتة، 2004-2018 (رام الله: 2019)، ص 77-78، شوهد في 2020/10/15، https://bit.ly/353pdB4 في الجركري

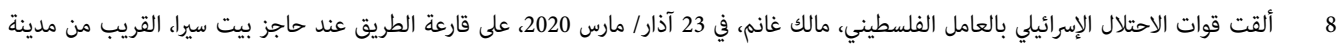

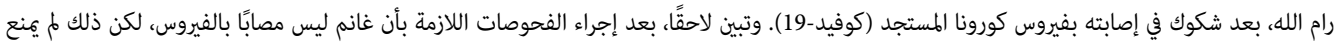

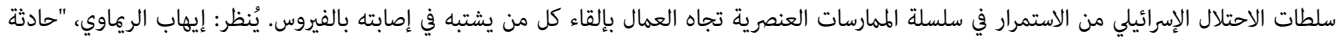
العامل غانم تفضح العنصرية الإسرائيلية،" وكالة الأنباء والمعلومات الفلسطينية "وفا"، 2020/3/24، شوهد في 
تقترح هذه الدراسة سياسة عامة تتسق مع مبادئ القانون الدولي الإنساني وقواعده، والقانون الدولي لحقوق الإنسان، وهي تتضمن مستويين متداخلين: أولهما دولي وإقليمي، يسعى إلى تعزيز المساعي القانونية لحماية حقوق العاملين الفلسطينيين

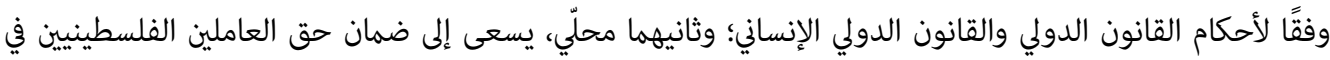
إنشاء نقابة فلسطينية مستقلة تحمي حقوقهم من الاستغلال الإسرائيلي. وقبل ذلك، تعرض الدراسة الإثكالية الرئيسة للعاملين الفلسطينيين، وتقدّم تشخيصًا معمقًا للتحديات التي تواجههم، وتفكك السياسة الفلسطينية تجاههمه.

\section{أولًا: تشخيص إشكالية العاملين الفلسطينيين وتوقعات نموها}

\section{1. الانتهاكات التي يتعرض لها العمال الفلسطينيون}

تُقر هذه الدراسة بأن قُدرة سوق العمل الإسرائيلية على استقطاب العاملين الفلسطينيين وجذبهم بأجر إشكاليةٌ مهمة من

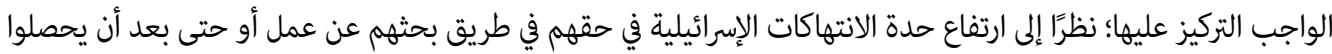

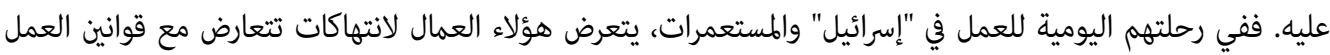

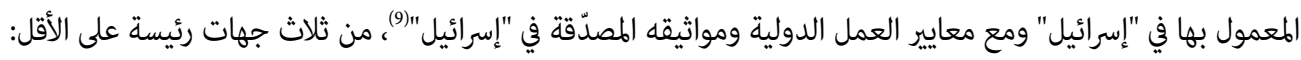

\section{أ- انتهاكات من سلطة الاستعمار الإسرائيلي}

تتخذ هذه الانتهاكات أشكالًا عدة ضد العاملين الفلسطينيين بأجر في "إسرائيل" والطستعمرات، كالابتزاز والإذلال وامتهان الكرامة، وذلك بالضغط عليهم من أجل التعاون مع جهاز المخابرات الإسرائيلي مقابل الحصول على تصريح

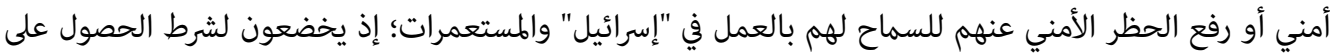
تصريح أمني قبل منحهم تصريح العمل (10). وتستمر هذه الانتهاكات حتى بعد حصولهم على تصريح أمني صادر عن سلطة المستعمِر الإسرائيلي يسمح لهم بالعمل، إذ يُعدّ الوصول إلى العمل في حد ذاته عملية معقدة وصعبة؛ فلا يتمتع هؤلاء العمال بحقهم في الوصول

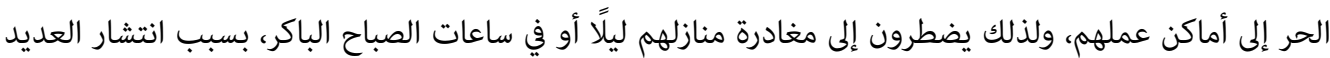

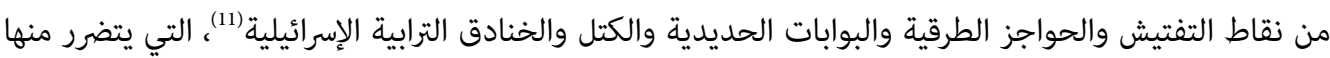
العمال لاكتظاظها وغياب المرافق الصحية عنها، وفقدانها لأماكن مخصصة تحميهم من البرد والحر (12). إضافة إلى ذلك، وتحديدًا فيما يخص العاملين الفلسطينيين بأجر في المستعمرات الإسرائيلية المقامة على أراضي الضفة

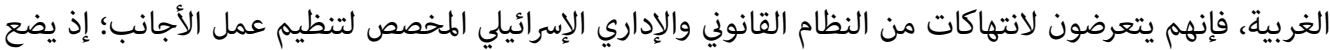

$$
9
$$

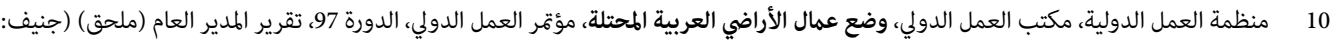

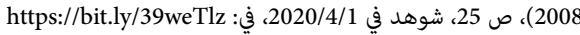

11 مركز ماكرو للاقتصاد السياسي، ظروف عمل العاملين بالأجر من الفلسطينيين في إسرائيل (تل أبيب: 2017)، ص 24-25، شوهد في 2020/4/1، في: https://bit.ly/3dNC8Le

12 منظمة العمل الدولية، مكتب العمل الدولي، وضع عمال الأراضي العربية المحتلة، مؤتر العمل الدولي، الدورة 102، تقرير المدير العام (ملحق)

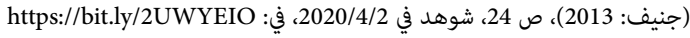


النظام العمل الذي يقوم به العمال الفلسطينيون في المستعمرات خارج إطار أي حماية مستحقة (13)، الأمر الذي يدفع أصحاب العمل الإسرائيليين في المستعمرات إلى تطبيق القانون الأردني لعام 1967، وهو أقل ملاءمة في تنظيم علاقات العمل بين العمال الفلسطينيين وأصحاب العمل، وفي المقابل يُطبق أصحاب العمل القوانين الإسرائيلية على العاملين الإسرائيليين في المناطق نفسها بنان.

وينطبق الأمر نفسه على العاملين الفلسطينيين بأجر في "إسرائيل" تحديدًا، فعلى الرغم من تنظيم قانون العمل

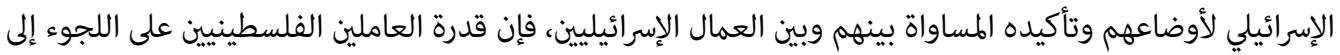

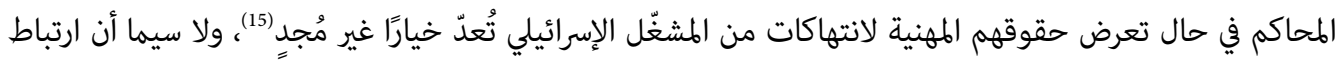
العمال الفلسطينيين بأصحاب العمل، وهم الفئة المخولة بمنح تصريح العمل أو سحبه، يؤدي إلى الضغط على على العمال العمال لقبول أوضاع تعسفية، خوفًا من فقدان وظائفهم أو خوفًا من طردهم من العمل بسبب وضعهم غير الفير القانوني (16.).

\section{ب- انتهاكات من الوسطاء أو السماسرة}

يتعرض العاملون الفلسطينيون بأجر في "إسرائيل" والمستعمرات لانتهاكات أخرى من الوسطاء أو السماسرة بين

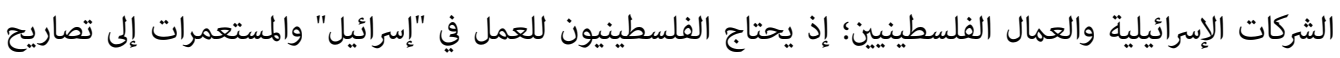

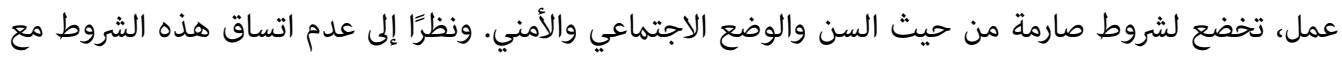
جميع الفلسطينيين الباحثين عن فرص عمل، يضطر العديد منهم إلى شراء التصاريح بطريقة غير قانونية؛ بدفع مبلغ

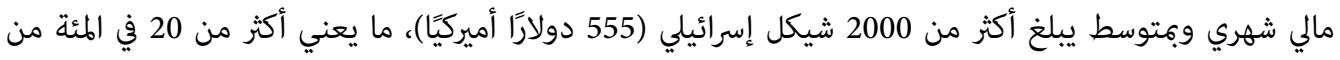

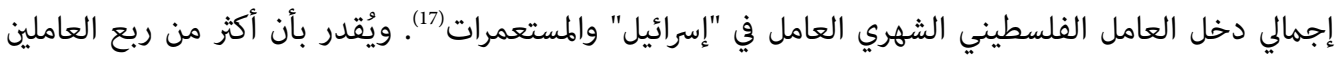

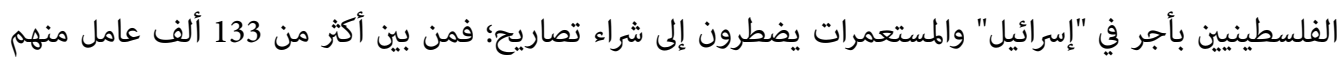

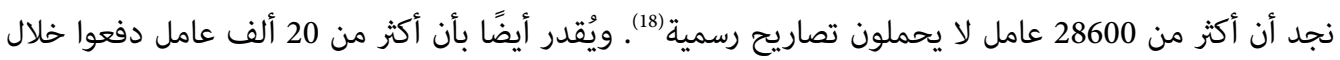
عام 2018 أكثر من نصف مليار شيكل إسرائيلي (140 مليون دولار أميركي) للوسطاء والشركات وأصحاب العمل الإسرائيليين للحصول على تصاريح عمل (19).

وعلى الرغم من مخالفة إصدار تصاريح خاصة للفلسطينيين للعمل في "إسرائيل" والمستعمرات المادة (37) من اتفاقية باريس (وهي تسمية متداولة للبروتوكول الاقتصادي الملحق باتفاقية غزة - أريحا الموقعة بين منظمة التحرير

13 منظمة العمل الدولية، مكتب العمل الدولي، وضع عمال الأراضي العربية المحتلة، مؤتمر العمل الدولي، الدورة 100، تقرير المدير العام (ملحق)

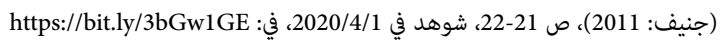
14

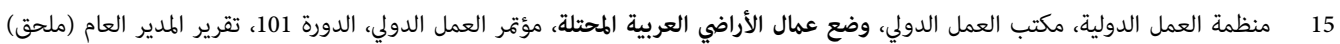

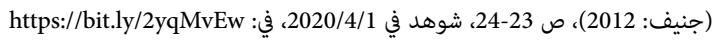

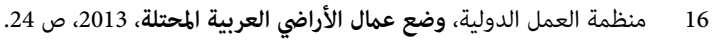

17 "Illegal Trade in Work Permits for Palestinian Workers in Israel," Bank of Israel, 25/9/2020, accessed on 4/4/2020, at: https://bit.ly/2Xf7S5Q

18 الجهاز المركزي للإحصاء الفلسطيني، مسح القوى العاملة: دورة (تشرين أول-كانون أول، 2018)، الربع الرابع 2018 (رام الله: 2019)، ص 16-17، شوهد في 2020/10/11، في: https://bit.ly/2xTrEcs

19 "Illegal Trade in Work Permits for Palestinian Workers in Israel." 
الفلسطينية و"إسرائيل" في 29 نيسان/ أبريل 1994)(20)، ومخالفتها أيضًا اتفاقية العمل الدولية رقم (34) بشأن مكاتب التوظيف بمقابل (21)، فإنه لا يكن العامل الفلسطيني الحصول على فرصة عمل في "إسرائيل" والمستعمرات من دون الحصول على تصريح عمل. وفي حال تعذّر الحصول على التصريح، فإن العامل الفلسطيني يلجأ إلى المشغل الإسرائيلي أو إلى سماسرة التصاريح من أجل الحصول على تصريح عمل، والنتيجة الحتمية عند صدوره هي وضع العامل تحت رحمة سماسرة التصاريح والمشغل الإسرائيلي، بوصفهما المتحكمين الرئيسين في مصير العامل الفلسطيني(22).

\section{ج- انتهاكات من المشغّلين الإسرائيليين}

يتعرض العاملون الفلسطينيون بأجر في "إسرائيل" والمستعمرات إلى انتهاكات من المشغّلين الإسرائيليين، وهي تتعارض مع القوانين المعمول بها في "إسرائيل" ومعايير العمل الدولية ومواثيقه المصدّقة من المستعمِر الإسرائيلي. وقد لوحظ زيادة غير مسبوقة في التمييز العنصري وانعدام المساواة في حق العاملين الفلسطينيين من المشغّلين الإسرائيليين؛ إذ يتلقى هؤلاء العاملون أجورًا دون الحد الأدنى المحدد في القانون الإسرائيلي، ويعملون ساعات تتجاوز ساعات العمل لدى العامل الإسرائيلي، كما أن أصحاب العمل يتلاعبون بأيام العمل للتأثير في حقوق العاملين المالية (23.). وكثيرًا ما أُبلغ العاملون الفلسطينيون بعدم وجود آليات ملزمة للمشغّلين الإسرائيليين عن الإجازة المَرَضية أو السنوية أو بدل العمل الإضافي، فلا يحصل العديد منهم على إجازات سنوية أو مَرَضية أو مدفوعة الأجر أو إعانات أو تأمين صحي؛ وذلك لافتقارهم إلى عقود عمل واضحة ومحددة مكتوبة أو فردية أو جماعية مع أصحاب العمل توفر لهم الحقوق والإعانات(24). وينطبق الحال نفسه على الفلسطينيين العاملين بعقود عمل واضحة ومحددة؛ إذ أُبلغوا أن أصحاب العمل يُسجلون عدد أيام أقل من أيام العمل الفعلية، وذلك لتجنّب دفع الإعانات الاجتماعية (25). بناءً على ما سبق، وفي حال بقاء الأمور على حالها، من المتوقع أن تتضاعف الانتهاكات في حق العاملين الفلسطينيين بأجر في "إسرائيل" والمستعمرات، بافتراض استمرار عدم التزام سلطات الاستعمار الإسرائيلي والطشغّلين الإسرائيليين بتطبيق القوانين والمواثيق الدولية التي تكفل حقوق العاملين الفلسطينيين، واستمرار تحكم سماسرة التصاريح من الوسطاء والشركات وأصحاب العمل في نظام تصاريح العمل. وما يُساهم في تزايد هذه الانتهاكات هو استمرار ارتفاع

$$
\text { أعداد العاملين الفلسطينيين في "إسرائيل" والطستعمرات. }
$$

20 تحدي 20

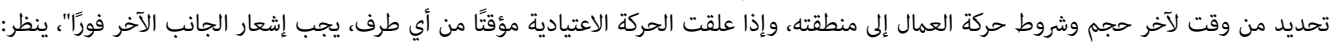

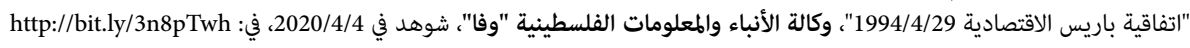

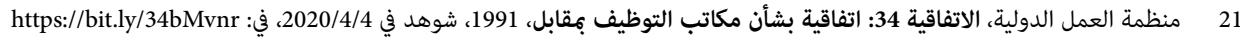

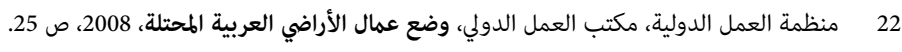
2323 24 24 25 (جنظمة العمل الدولية، مكتب العمل الدولي، وضع عمال الأراضي العربية المحتلة، مؤتمر العمل الدولي، الدورة 107، تقرير المدير العام (ملحق)

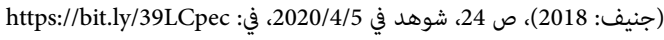




\section{2. أعداد العاملين الفلسطينيين بأجر في "إسرائيل" والمستعمرات}

يتزايد تدفق العاملين الفلسطينيين في "إسرائيل" والطستعمرات سنويًا، ففي نهاية عام 2019 بلغ عددهم أكثر من

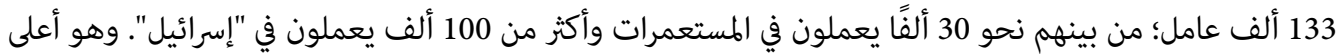
رقم مُسجل منذ بدء الفلسطينيين العمل في "إسرائيل" والمستعمرات في أواخر ستينيات القرن العشرين (ينظر الشكل الذي يبين عدد هؤلاء في الفترة 1970-2019)، ويمثل هؤلاء نحو 13.2 في المئة من إجمالي التوزيع النسبي للعاملين في الضفة الغربية وقطاع غزة من سن 15 سنة فأكثر (26).

شكل يبيّن عدد العاملين الفلسطينيين بأجر في "إسرائيل" والمستعمرات (1970-2019)

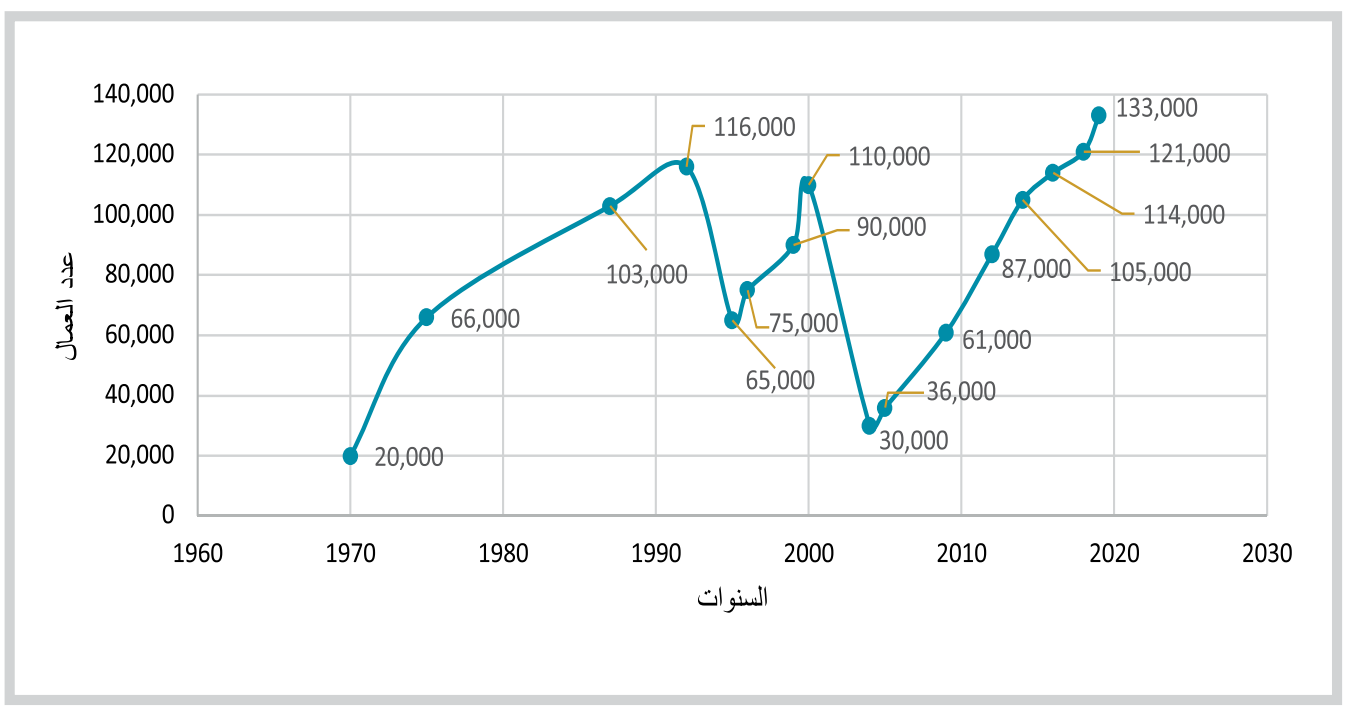

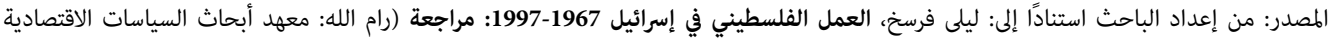

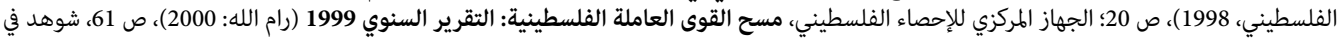

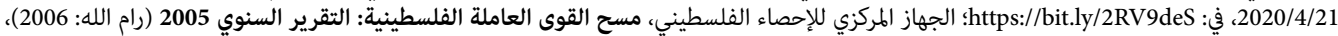

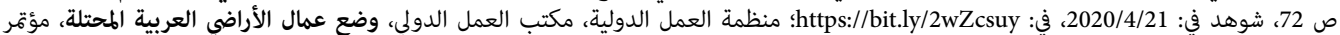

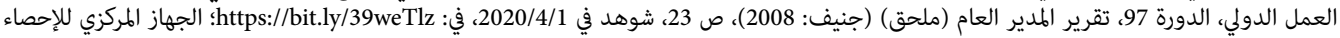

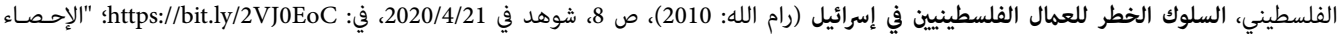

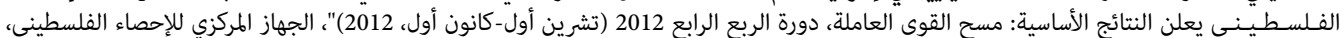

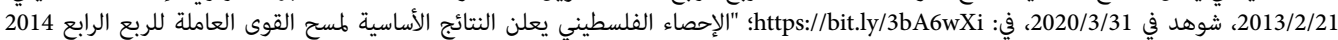

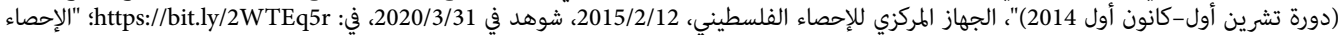

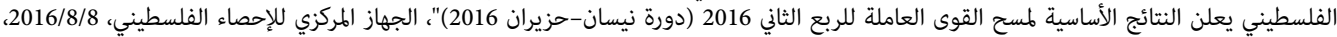

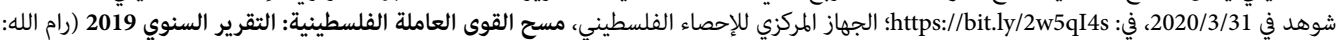

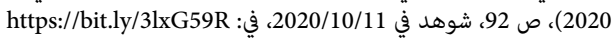

وفي السياق نفسه، يُلاحظ منذ عام 2005 ارتفاع معدلات العاملين الفلسطينيين بأجر في "إسرائيل" والمستعمرات،

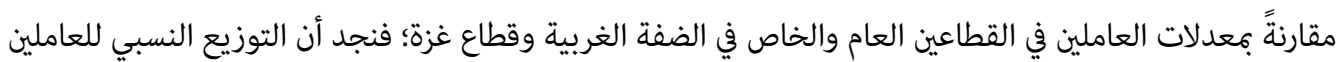
في "إسرائيل" والمستعمرات ارتفع من 9.3 في المئة عام 2005 إلى 13.2 عام 2019، في مقابل تراجع التوزيع النسبي للعاملين في القطاع العام من 22.5 في المئة عام 2005 إلى 20.7 عام 2019، وتراجع التوزيع النسبي للعاملين في 
القطاع الخاص من 68.2 في المئة عام 2005 إلى 66.1 في المئة عام 2019(27.). وينطبق الحال نفسه عند مقارنة معدلات

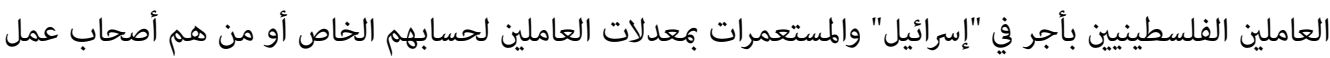
في الضفة الغريبة وقطاع غزة؛ فقد انخفضت الأخيرة من 26.1 في المئة عام 2005 إلى 18.1 في المئة عام 2019 (28. وما يعزز ذلك هو ارتفاع معدل الأجر اليومي للعامل الفلسطيني في "إسرائيل" والمستعمرات مقارنةً بالأجر اليومي للعامل الفلسطيني في الضفة الغربية وقطاع غزة. وإذا ما قارنّا أجر العامل الفلسطيني في "إسرائيل" والطستعمرات بأجر العامل الفلسطيني في القطاعين العام والخاص نجد أنه أعلى بكثي؛ ففي عام 2019، بلغ متوسط الأجر اليومي للعامل الفلسطيني في "إسرائيل" والمستعمرات أكثر من ضعف متوسط الأجر اليومي للعامل الفلسطيني في القطاعين العام والخاص في الضفة، وكذلك أكثر من أربعة أضعاف متوسط الأجر اليومي للعامل الفلسطيني في القطاعين العام والخاص في غزة (29).

وثمة ثلاثة مؤشرات رئيسة تدل على إمكانية استمرار ارتفاع معدلات هجرة العمال الفلسطينيين للعمل بأجر في "إسرائيل" والطستعمرات. أولها تنامي القوة الديموغرافية للفلسطينيين في الضفة الغربية وقطاع غزتة، التي تضاعفت

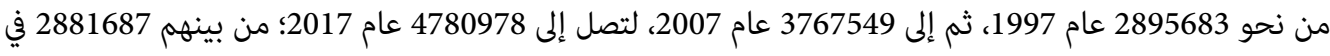
الضفة الغربية، و 1899291 في قطاع غزة (30. أما المؤشر الثاني، فهو ارتفاع معدلات مشاركة القوى العاملة الفلسطينية في سوق العمل الفلسطيني، وتُشير نتائج التعداد العام للسكان والطساكن إلى أن تضاعف القوة الديموغرافية للفلسطينيين منذ عام 1997 ساهم على نحو رئيس في توسيع شريحة القوى العاملة المؤهلة للعمل لمن أعمارهم 15

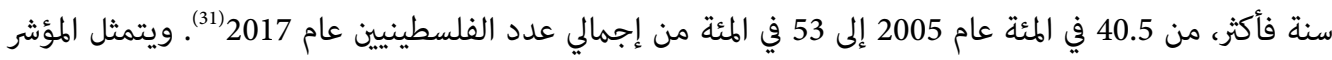
الثالث في تباين قدرة الاقتصاد الفلسطيني على استيعاب تنامي قوة العمل للفلسطينيين الباحثين عن فرص عمل (32 فئن

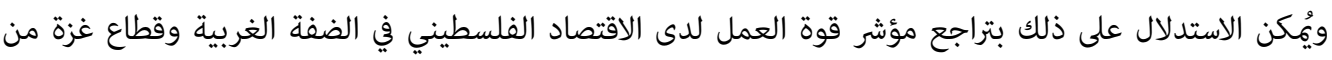

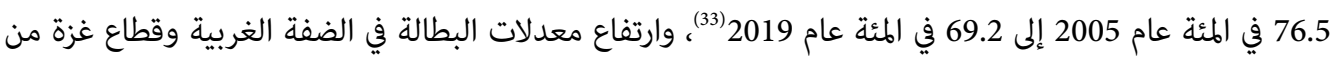
23.5 في امئة عام 2005 إلى 38 في المئة عام 2019، وتنامي معدلات الفقر التي وصلت نسبًا غير معهودة، فأكثر من ربع الفلسطينيين خلال الربع الأول من عام 2020 يعانون الفقر؛ من بينهم 30 في المئة في الضفة الغربية، و64 فئ في فئه المئة في قطاع غزة (34).

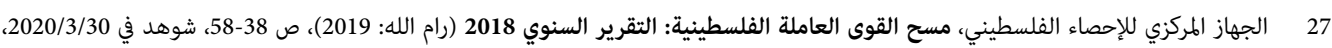

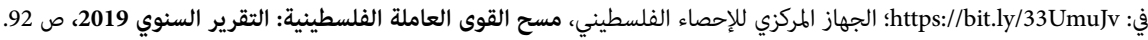

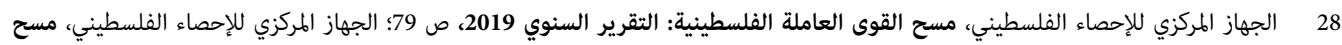

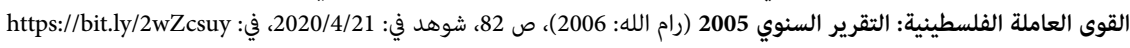
2929

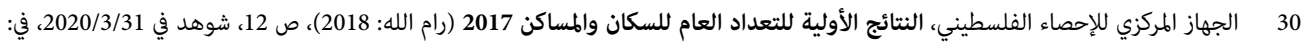
https://bit.ly/2ymOJVr

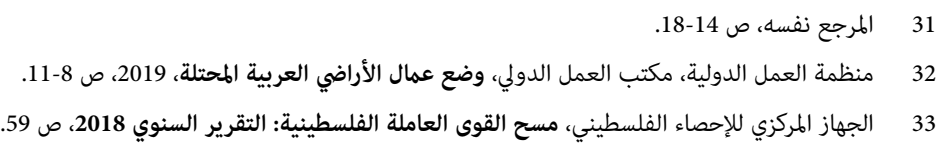
34 "Palestinian Economy Struggles as Coronavirus Inflicts Losses," The World Bank, 1/6/2020, accessed on 12/10/2020, at: https://bit.ly/3lCa4xj 
وبناءً على ما سبق، وفي حال بقاء الأمور على حالها، من المتوقع أن تتضاعف أعداد الفلسطينيين العاملين في "إسرائيل" والمستعمرات، بافتراض استمرار النمو الديموغرافي للفلسطينيين، واستمرار توسع شريحة القوى العاملة الباحثة عن فرص عمل، وضعف قدرات الاقتصاد الفلسطيني على استيعاب الباحثين عن فرص عمل. وما يساهم في تزايد حجم

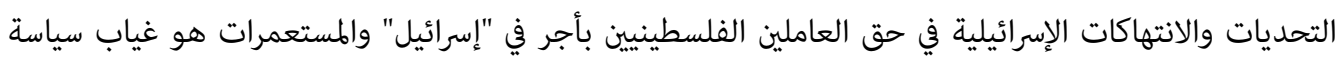
عامة فلسطينية تحمي حقوقهم.

\section{ثانيًا: السياسة الفلسطينية الراهنة تجاه العاملين الفلسطينيين بأجر في "إسرائيل: الميأ المستعمرات}

أصدرت السلطة الفلسطينية قرارًا بقانون رقم (4) لعام 2010 بشأن "حظر ومكافحة منتجات المستوطنات"، وأقرت في المادة رقم (5) تبني الحكومات في خططها سياسات وبرامج ومشاريع تهدف إلى مكافحة أيّ عمل يتمثل في نشاط تقني أو حرفي أو مادي في المستعمرات من شأنه تقديم منفعة لها لقاء مقابل مالي، ونصت في المادة رئي رقم تأسيس صندوق مالي يُساهم في قكين الفلسطينيين وحماية حقوقهم من الاستغلال (35).

وعلى الرغم من ذلك، مل تتبنَ الحكومة الفلسطينية في "خطة التنمية الوطنية 2011-2013" التي كان عنوانها "إقامة الدولة وبناء المستقبل" سياسة عامة بشأن العاملين الفلسطينيين بأجر في المستعمرات؛ فخطة التنمية الوطنية، وإن إن أشارت في سياستها الخاصة بقطاع التنمية الاقتصادية في هدفها الخاص "محاربة البطالة وتعزيز سوق العمال" إلى بـاءين

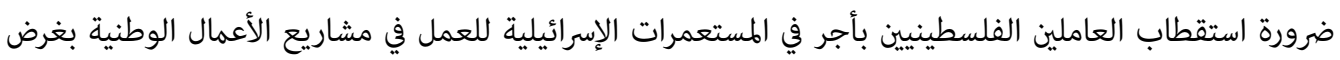
حمايتهم من الاستغلال الإسرائيلي، فإنها مل تعكس هذه الضرورة في تدخلاتها السياساتية، فقد ركزت على تدخلات، مثل: تفعيل الشراكة بين القطاعين العام والخاص والهيئات غير الحكومية من أجل توفير مشاريع استثمارية للشباب الهناب والنساء، وتطوير قدرات الشباب في التدريب المهني وتعزيزها، وإطلاق صندوق التشغيل والحماية الاجتماعية للشباب، وتنظيم سوق العمل ومراقبته (36).

أما "خطة التنمية الوطنية 2014-2016"، التي كان عنوانها "بناء الدولة وتجسيد السيادة"، فإنها ملم تُشر أيضًا في أولوياتها أو سياساتها الوطنية إلى تبنّي سياسة عامة بشأن تنظيم أوضاع العاملين الفلسطينيين في المستعمرات. فقد التهاء

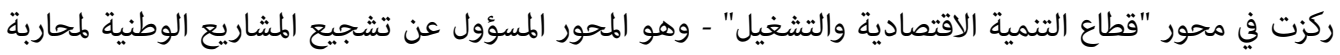

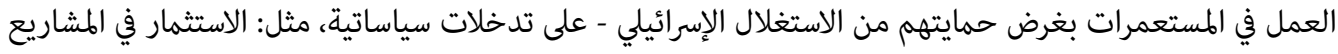

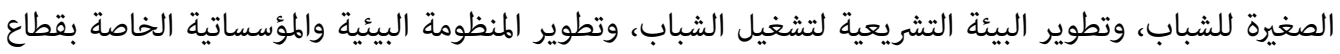

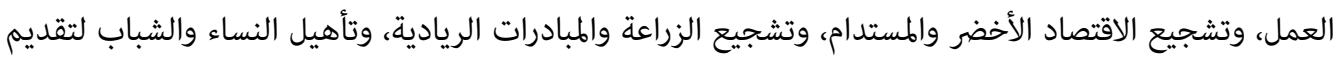
مبادرات اقتصادية (37).

35 قرار بقانون رقم (4) لسنة 2010م بشأن حظر ومكافحة منتجات المستوطنات، المقتفي: منظومة القضاء والتشريع في فلسطين، 2020/4/10/4/26، شوهد

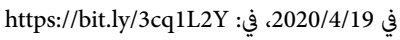

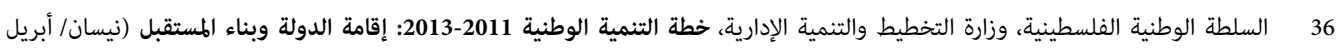

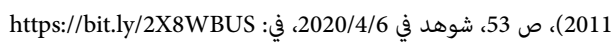
37 دولة فلسطين، خطة التنمية الوطنية 2014-2016، 23 شباط/ فبراير 2014، ص 22-25، شوهد في 2020/4/6، في: https:/bit.ly/34fmljP 
وطم تتبنَ "أجندة السياسات الوطنية 2017-2022"، وعنوانها "المواطن أولًا"، في أولوياتها أو سياساتها الوطنية، سياسةً

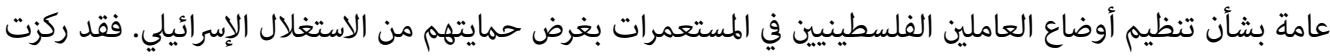

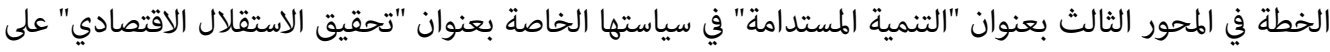

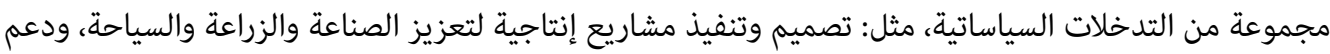

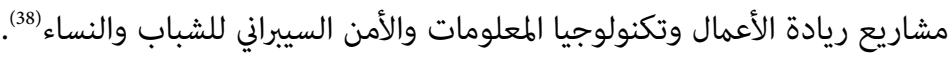

إضافة إلى ذلك، لم تتبنَ الحكومة الفلسطينية أي سياسة عامة تجاه العاملين الفلسطينيين بأجر في "إسرائيل"، نظرًا

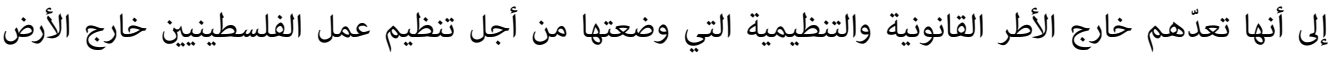

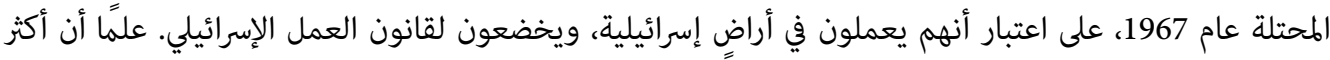

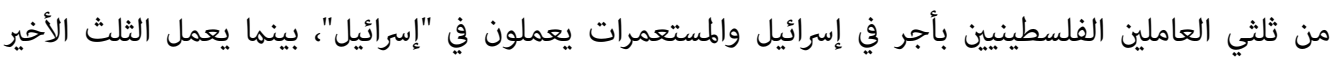

$$
\text { في المستعمرات الإسرائيلية. }
$$

ومنذ عام 2011، نجد أن بند النفقات التطويرية في موازنة الحكومة الفلسطينية، وتحديدًا البند الخاص بالقطاع الاقتصادي المسؤول عن تبنّي خطط وسياسات وبرامج ومشاريع لكافحة العمل في المستعمرات، يفيد أن الحكومات

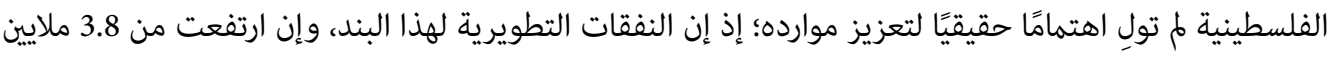

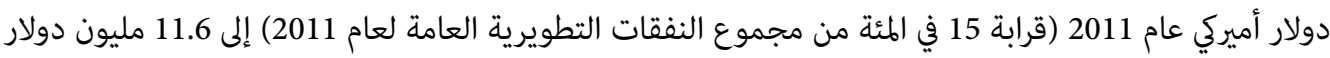
أميركي عام 2018 (قرابة 13 في المئة من مجموع النفقات التطويرية العامة لعام 2018)، فإن توزيع النفقات يُبيّن أن القطاع المسؤول عن التشغيل يأتي في المرتبة الرابعة ضمن أولويات الحكومة القطاعية، بعد قطاعات الحكمم والتنمية

الاجتماعية والبنية التحتية (39).

\title{
ثالثًا: ما السياسة المقترحة؟
}

\author{
تتضمن السياسة المقترحة مستويين:
}

\section{1. المستوم الإقليمي والدوليي}

يتمثل في اللجوء إلى القانون الدولي ضمن اعتبارٍ يضمن للحكومة الفلسطينية تعزيز المساعي القانونية لحماية

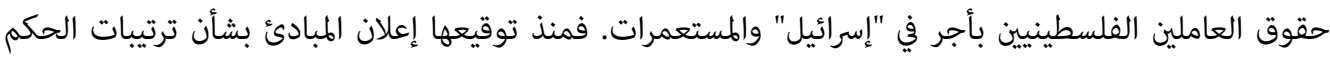

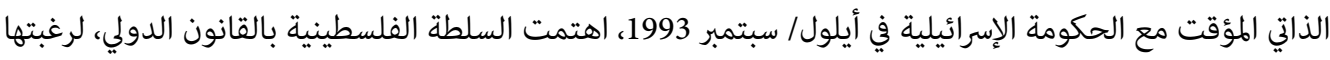
في المحافظة على وضعها ضمن منظومة المجتمع الدولي، وتماشيه مع طموحها إلى الانتقال من سلطة حكم ذاتيه

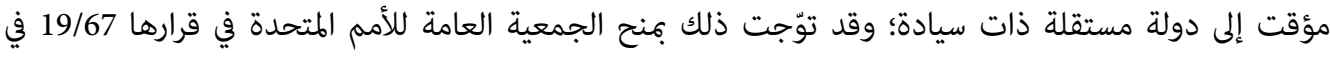
29 تشرين الثاني/ نوفمبر 2012، فلسطين مركز دولة غير عضو، لها صفة المراقب في الأمم المتحدة.

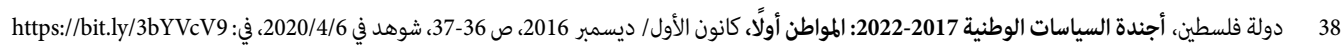

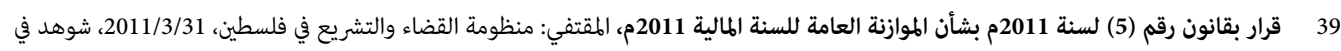

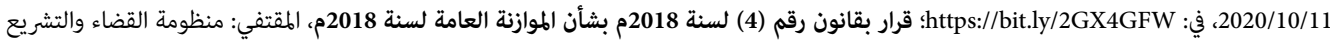
في فلسطين، 2018/3/4، شوهد في 2020/10/11، في: قرار بقانون رقم 
على الرغم من هذا الاهتمام، فإن السلطة الفلسطينية لم تستفد من القانون الدولي في تعزيز المساعي القانونية لحماية حقوق العاملين الفلسطينيين بأجر في "إسرائيل" والمستعمرات؛ نظرًا إلى رهن انضمامها إلى أي منظمة أو اتفاقية دولية أو حصولها على قرار دولي أو تقديها شكوى ضد الانتهاكات الإسرائيلية بالإطار المصمم لأي مفاوضات مستقبلية مع "إسرائيل"، وحرصًا منها على عدم تأثير ذلك في مساعيها للحصول على "دولة فلسطينية" على حدود الرابع من حزيران/ يونيو 1967. وحتى حينما اعتمدت السلطة الفلسطينية على القانون الدولي، ولا سيما اتفاقية جنيف الرابعة بشأن حماية الأشخاص المدنيين وقت الحرب، بوصفها مرجعية قانونية تحدد العلاقة بين سلطة الاحتلال والسكان الأصليين للأرض المحتلة، فإنها لم تستفد منها؛ لأنها لا تنطبق إلا على الأرض المحتلة بعد حرب حزيران/ يونيو 1967، ما يعني استثناء الأرض المحتلة عام 1948، واستثناء الفلسطينيين الموجودين في الأرض نفسها، واستثناء اللاجئين الفلسطينيين المقيمين خارج فلسطين.

ومع ذلك، من غير المحبذ أن يُدير الفلسطينيون ظهورهم للقانون الدولي؛ لأن في مقدوره - إن استعمل استعمالًا

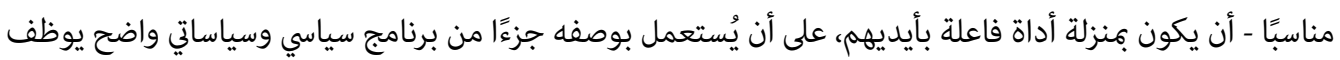
القانون، وليس استراتيجية قانونية تحدد السياسة، وعلى أن يقترن ذلك بتولي المؤسسات العمومية الفلسطينية، فضلًا عن مهمات تسيير حياة الفلسطينيين اليومية في القضايا الخدماتية والاقتصادية والتنموية والأمنية، مهمة تعزيز المساعي القانونية لحماية حقوق الفلسطينيين السياسية والاقتصادية والاجتماعية، من خلال توليها مسؤولية رصد الانتهاكات الإسرائيلية ضد الفلسطينيين ومتابعتها مع المنظمات والهيئات والمحاكم الإقليمية والدولية، وذلك جنبًا إلى جنب مع عمل لجان الأمم المتحدة وبعثاتها ومقرريها وهيئاتها المنشأة بكوجب القانون الدولي.

ويُمكن النظر هنا إلى تجربة الفلسطينيين مع الرأي الاستشاري الصادر عن محكمة العدل الدولية في 9 توز / يوليو 2004 بشأن جدار الفصل العنصري الذي طلب من "إسرائيل" التوقف عن بنائه، وتفكيك أجزاء منه، وإلغاء الأوامر الصادرة بخصوص إقامته، وتعويض المتضررين منه. وكذلك قرار مجلس الأمن 2334 الصادر في 23 كانون الأول/ ديسمبر 2016 بشأن الاستيطان الإسرائيلي في الأراضي الفلسطينية المحتلة الذي نص على ضرورة وقف الاستيطان الإسرائيلي في الضفة الغربية بما فيها القدس الشرقية، وعدم شرعية المستوطنات الإسرائيلية الجديدة، وإدانة التغييرات الديموغرافية التي تشمل توسيع المستوطنات ونقل المستوطنين الإسرائيليين ومصادرة الأراضي وهدم المنازل وتشريد المدنيين. هذان القراران، على ما فيهما من قصور، منحا الفلسطينيين فرصة لحماية حقوقهم من الاستغلال الإسرائيلي. أما العاملون الفلسطينيون بأجر في "إسرائيل" والمستعمرات، فيُمكنهم الاستفادة من القوانين والمواثيق الدولية التي تنظم مجال العمل، والتي تضمن لهم العمل في شروط عادلة ومُرضية. كما يُكن الاستعانة بالإعلان العالمي لحقوق الإنسان، مع التركيز على المادتين (23) و(24)(40)، والعهد الدولي الخاص بالحقوق الاقتصادية والاجتماعية والثقافية، 
واتفاقية جنيف الرابعة بشأن حماية الأشخاص المدنيين وقت الحرب، مع التركيز على المواد (39) و(40) و(52)(41)، واتفاقية منظمة العمل الدولية رقم (169) بشأن الشعوب الأصلية والقبلية، والاتفاقية الدولية لقمع جريمة الفصل العنصري والمعاقبة عليها، مع التركيز على المادة رقم (2) في الفقرة (ج) (22)، والاتفاقية الدولية للقضاء على جميع أشكال التمييز العنصري، مع التركيز على المادة رقم (5)(43). فجُّ هذه البنود يكفل حماية حقوق العاملين الفلسطينيين بأجر في "إسرائيل" والطستعمرات ويدين الانتهاكات الإسرائيلية التمييزية في حقهم، بوصفها انتهاكات تسلب حقهم في العمل، وحقهم في حرية اختيار العمل، وحقهم في شروط عمل عادلة ومُرضية، تكفل السلامة والصحة والعيش الكريم، وحقهم في أجر متساوٍ، وحقهم في مكافآت وإجازات وعطل عادلة ومُرضية، وحقهم في الراحة، وحقهم في تحديد ساعات العمل، وحقهم في محاكمة عادلة، وحقهم في وصول آمن إلى مكان العمل. على المدى الطويل، يُكن الفلسطينيين المساهمة في اقتراح قانون لوصم نظام تصاريح العمل الذي يطبق على العاملين الفلسطينيين بأجر في "إسرائيل" والطستعمرات، بوصفه عبودية حديثة. كما يكن اقتراح قانون لوصم النظام القانوني والإداري الذي يطبق على العمال الفلسطينيين، بوصفه قيييزًا على أساس قومي عنصري. ويمكن أيضًا اقتراح قانون لوصم الاستقطاعات من أجور العمال الفلسطينيين، بوصفها سرقة أموال السكان الأصليين ومصادر رزقهم. ويككن

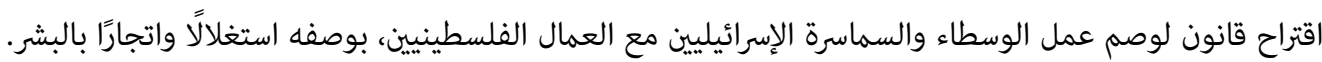
بهذه الطريقة، يمكن أن يكون القانون الدولي بمنزلة أداة فاعلة بأيدي الفلسطينيين؛ فمن جهة سيضمن حقوق العاملين الفلسطينيين بأجر في "إسرائيل" والطستعمرات، ومن جهة أخرى سيتمكن هؤلاء العمال من الاستفادة من القانون الدولي في قييز "إسرائيل" وشركاتها التي تنتهك حقوقهم من باقي شركات العالم، ووصمها بوصفها شركات تساهم في تكريس نظام الاستعمار الاستيطاني العنصري، وكذلك سيكون في مقدور العمال إدانة الدول والمنظمات والشركات والأفراد المتعاملين معها ومحاسبتهم، بوصفهم متورطين في دعم النظام الاستعماري العنصري.

41 تنص المواد (39) و(40) و(52) من اتفاقية جنيف الرابعة بشأن حماية الأشخاص المدنيين وقت الحرب، كما تنص المادة (6) من العهد الدولي الخاص

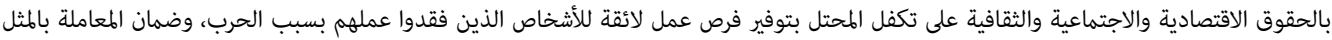

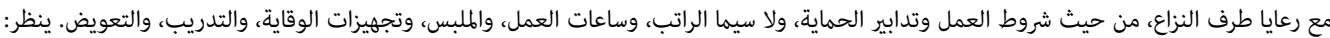

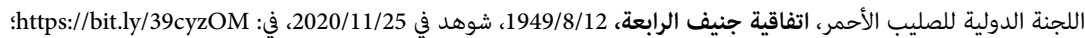
Office of the United Nations High Commissioner for Human Rights (OHCHR), International Covenant on Economic, Social and Cultural Rights, 16/12/1966, accessed on 26/11/2020, at: https://bit.ly/2J9NDlD

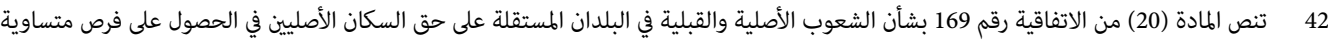

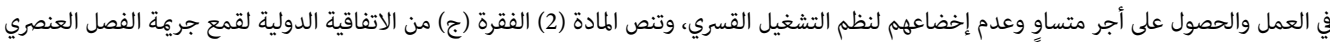

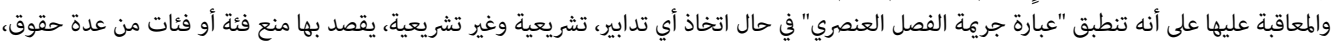

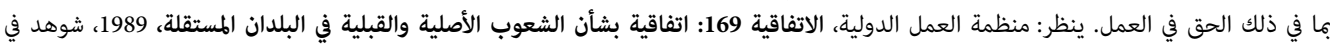
؛https://bit.ly/33isQTS في في الغمل: 2020/11/26

United Nations, General Assembly, International Convention on the Suppression and Punishment of the Crime of Apartheid, 1974, accessed on 25/11/2020, at: https://bit.ly/2UYoInk

43 تنص المادة (5) من الاتفاقية الدولية للقضاء على جميع أشكال التمييز العنصري على تعهد الدول الأطراف بحظر التمييز العنصري والقضاء عليه بكافة

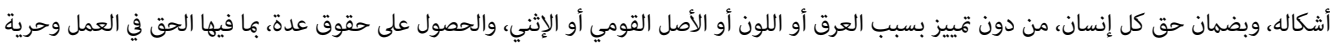

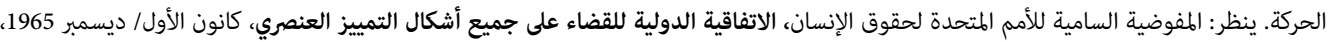

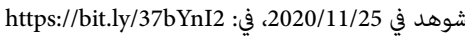




\section{2. (المستوn المحلي}

يكن دعم حق العاملين الفلسطينيين بأجر في "إسرائيل" والمستعمرات، محليًا بتأسيس نقابة عمالية فلسطينية مستقلة، تحمي حقوقهم وتساهم في دمجهم ضمن نضال سياسي يدعو إلى التحرر من الاستعمار، مع الاستفادة من

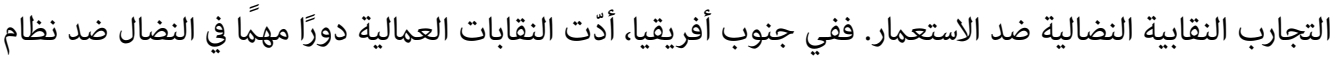
التمييز العنصري؛ إذ مل تكتفِ بالنضال الضيق المرتبط بالحقوق النقابية، بل ساهمت أيضًا في النضال السياسي للحركة الوطنية من أجل التحرر. فأولئك العمال لم يكونوا متقبلين سلبيين للأشكال العنصرية والقسرية للسيطرة على العمل،

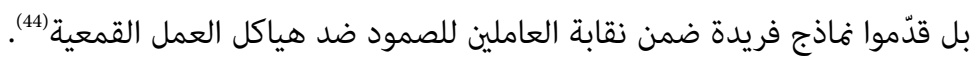

وفي فلسطين، تُناضل النقابات العمالية بطرق عدة ضد الاستعمار الإسرائيلي ونظام التمييز العنصري، منذ بداية المشروع الاستعماري في فلسطين. وقد انتقلت هذه النقابات عام 2011 إلى النضال ذي الصبغة العالمية من أجل تعزيز المساعي القانونية لحماية حقوق العاملين الفلسطينيين بأجر في "إسرائيل" والمستعمرات، وإدانة الانتهاكات الإسرائيلية في حقهم، مع تأسيسها "الائتلاف النقابي الفلسطيني لمقاطعة إسرائيل"، بوصفه أكبر تحالف نقابي فلسطيني يمثل الحركة النقابية العمالية والمهنية. ومنذ ذلك الحين، بدأت النقابات العمالية الفلسطينية في دعوة النقابات

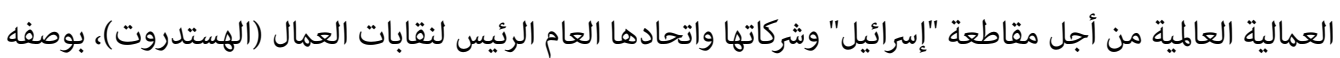

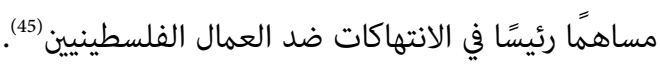

لا شكّ في أن غياب جسم تمثيلي فلسطيني للعمال الفلسطينيين في "إسرائيل" والمستعمرات، يتولى حماية حقوقهم ومصالحهم ويحارب ضد مظاهر استغلالهم، أمرٌ بالغ الأهمية. ونتيجة لذلك، فإن معظم العمال الفلسطينيين لا يعرفون أبسط حقوقهم التي تضمن عملهم بشروط عادلة ومُرضية تكفل سلامتهم وصحتهم، من دون ممارسة أي انتهاك أو تييز أو استغلال أو اضطهاد في حقهم. وقد أشار العديد من العمال إلى عدم وجود وعي كافٍ للمطالبة بحقوقهم (46). إن الاتحاد العام لنقابات عمال فلسطين (47) يستنزف جلّ وقته في متابعة استصدار تصاريح للعاملين الفلسطينيين في "إسرائيل" والطستعمرات، بدلًا من تنظيم المساعي القانونية لحماية حقوقهم ومتابعة تعزيزها ووقف فئف

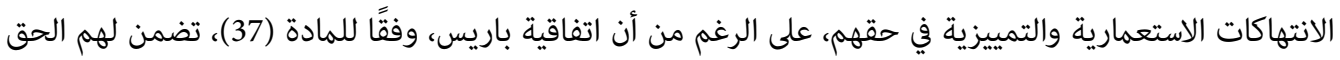

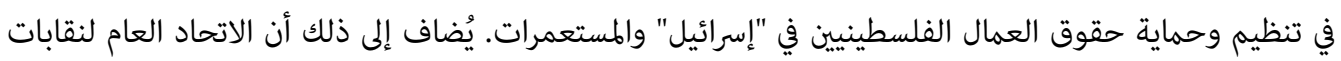
عمال فلسطين مُ يدعم على نحوٍ كافٍ ضمان حقوق العاملين الفلسطينيين في "إسرائيل" والمستعمرات عند بدء النقاش في فلسطين عام 2019 من أجل إقرار قانون الضمان الاجتماعي الفلسطيني؛ إذ اكتفى الاتحاد بطرح مسألة تحويل

44 Timothy Sizwe Phakathi, "Worker Agency in Colonial, Apartheid and Post-apartheid Gold Mining Workplace Regimes," Review of African Political Economy, vol. 39, no. 132 (2012).

45

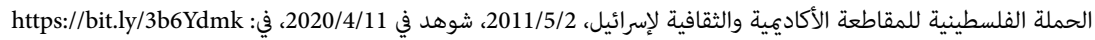

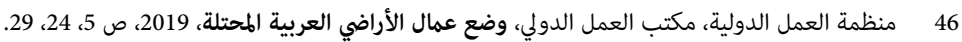

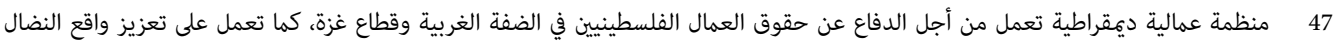

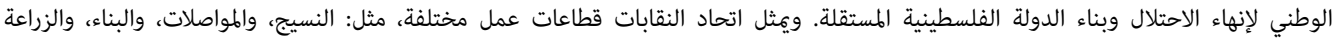
والصناعات الغذائية، والسياحة، والخدمات العامة، والهيئات المحلية، والبتروكيماويات، والمصارف والبنوك وشركات التأمين، والاتصالات، والخدمات الصحات الصحية. 
"إسرائيل" اشتراكات الضمان الاجتماعي التي جمعتها من العاملين الفلسطينيين في "إسرائيل" والمستعمرات منذ عام 1970، التي تبلغ نحو 30 مليار شيكل إسرائيلي (8.3 مليارات دولار أميركي)، إلى خزينة السلطة الفلسطينية (48). على نحو جوهري، يضمن إنشاء نقابة مستقلة للعاملين الفلسطينيين في "إسرائيل" والمستعمرات حق العاملين في النضال من أجل حقوقهم السياسية والنقابية؛ وهذا يعني الُُساهمة في النضال من أجل تحرير العامل الفلسطيني من قبضة نظام التمييز العنصري الإسرائيلي. ويمكن أن تطور هذه النقابة خطابًا فلسطينيًا يتعامل مع جميع العاملين الفلسطينيين في "إسرائيل" والمستعمرات القادمين من الضفة الغربية وقطاع غزة والأرض المحتلة عام 1948 على نحوٍ متساوٍ. ويمكنها كذلك أن تنضم إلى "الائتلاف النقابي الفلسطيني لقاطعة إسرائيل"، وبدء حملة دولية ضمن

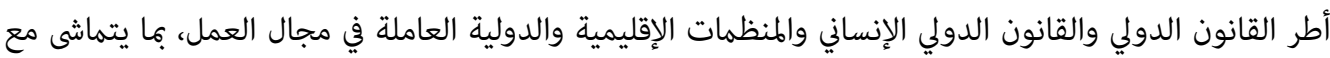
أحكام القانون الدولي لحماية حقوق العاملين الفلسطينيين وإدانة "إسرائيل" وشركاتها ونقابتها للعاملين، استنادًا إلى الأهداف الأربعة الواردة في الإعلان الخاص بشأن المبادئ والحقوق الأساسية في العمل (49)، والمادة رقم (2) من الاتفاقية الدولية لقمع جريمة الفصل العنصري والمعاقبة عليها(50)، والمادة رقم (5) من الاتفاقية الدولية للقضاء على جميع أشكال التمييز العنصري(51)، والهادة رقم (20) من اتفاقية منظمة العمل الدولية رقم (169) بشأن الشعوب الأصلية والقبلية (52).

\section{خاتمة}

يُعاني العاملون الفلسطينيون بأجر في "إسرائيل" والطستعمرات جملةً من التحديات، بما فيها غياب سياسة عامة فلسطينية تحمي حقوقهم من الاستغلال الاستعماري الإسرائيلي. وما يعزز تنامي هذه التحديات أن المؤسسات

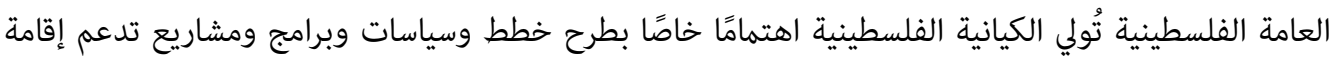
"الدولة الفلسطينية" وتجسيد السيادة على حدود الرابع من حزيران/ يونيو 1967. ومع أهمية ذلك، فإنه لا مفر من

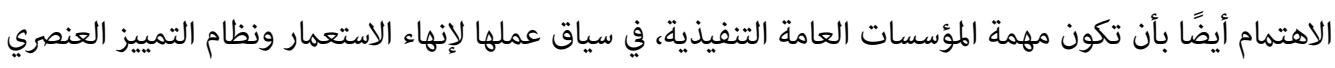
الإسرائيلي، منع استغلال العاملين الفلسطينيين بأجر في "إسرائيل" والطستعمرات.

48 سجود عاصي، "اتحاد نقابات العمال في فلسطين يعلن موقفه من قانون الضمان الاجتماعي"، الحدث، 2018/10/14، شوهد في 2020/4/11، في: https://bit.ly/2Rtj9Ms

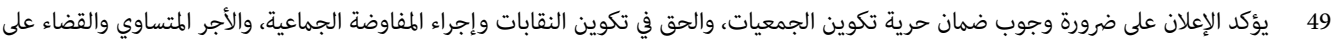

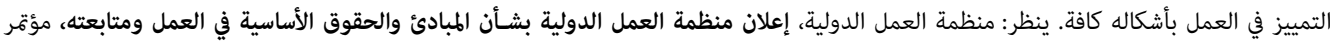

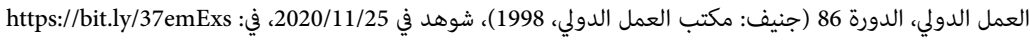

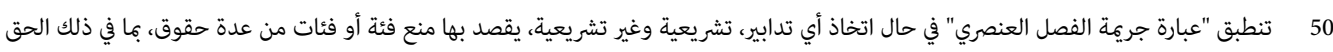
في تشكيل نقابات معترف بها. ينظر: United Nations, General Assembly, International Convention on the Suppression and Punishment of the Crime of Apartheid. 51 تضمن المادة (5) من الاتفاقية الدولية للقضاء على جميع أشكال التمييز العنصري حق جميع العاملين من تكوين نقابات والانتماء إليها. ينظر: المفوضية السامية للأمم المتحدة لحقوق الإنسان، الاتفاقية الدولية للقضاء على جميع أشكال التمييز العنصال التصري.

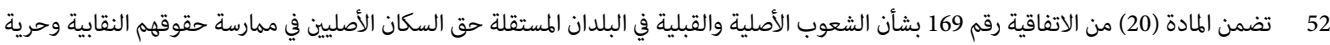

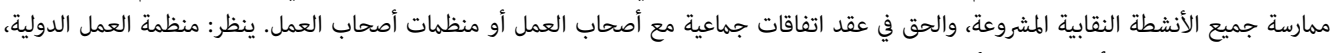
الاتفاقية 169: اتفاقية بشأن الشعوب الأصلية والقبلية في البلدان المستقلة. 
منذ عام 1968، ومع بدء تدفق العمالة الفلسطينية إلى "إسرائيل" والطستعمرات، يُعاني العمال الفلسطينيون غياب

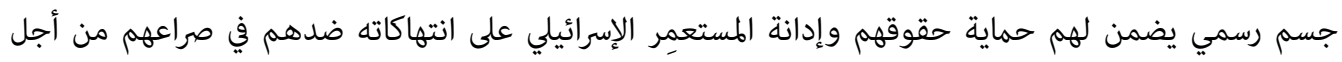

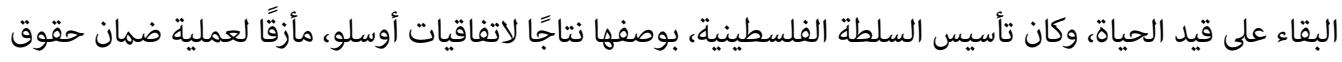
الفلسطينيين وحمايتها، بمن فيهم العاملون الفلسطينيون بأجر في "إسرائيل" والمستعمرات.

بناء عليه، بدا ملمًا الآن، في ضوء التحديات الماثلة أمام الفلسطينيين في سياق نضالهم من أجل إنهاء الاستعمار

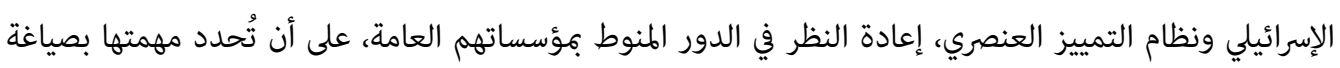

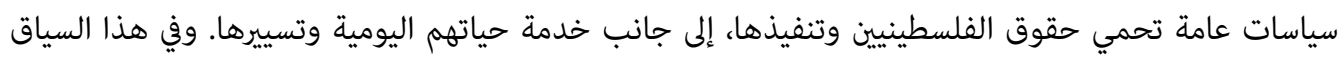

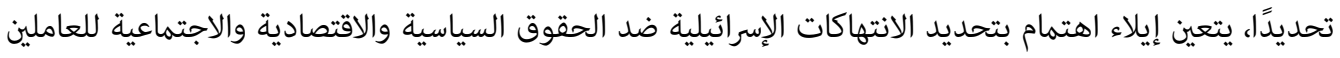

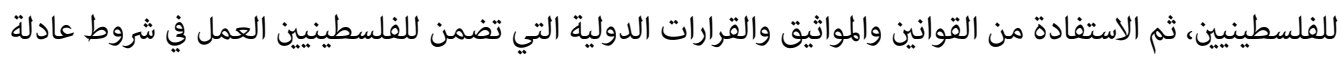
ومُرضية، وصولًا إلى المساهمة في اقتراح قوانين دولية جديدة تحمي حقوق العاملين الفلسطينيين بأجر في "إسرائيل" والمستعمرات وتجرم الانتهاكات الإسرائيلية في حقهم.

ويُقترح أيضًا دعم تأسيس نقابة عمالية مستقلة تضمن حقوق العاملين الفلسطينيين، مُستفيدة من تجارب نقابية

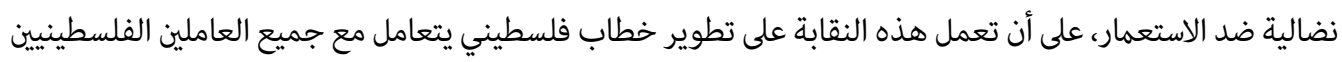
في "إسرائيل" والمستعمرات، القادمين من الضفة الغربية وقطاع غزة والأرض المحتلة عام 1948. كذلك من المساهمة في ضم العاملين الفلسطينيين في "إسرائيل" والمستعمرات إلى "الائتلاف النقابي الفلسطيني لمقاطعة إسرائيل". وبدء حملة دولية تتماشى مع أحكام القانون الدولي لمقاطعة إسرائيل وشركاتها ونقابتها للعاملين، استنادًا إلى القوانين والمواثيق والقرارات الدولية التي تحمي حقوقهم وتجرئ وتهرم "إسرائيل"، بوصفها استعمارًا استيطانيًا ونظام قتييزٍ عنصري.

أمام الفلسطينيين اليوم في ظل التحديات الماثلة فرصة مهمة للاستفادة من المؤسسات العامة القامٔة في إطار العمل

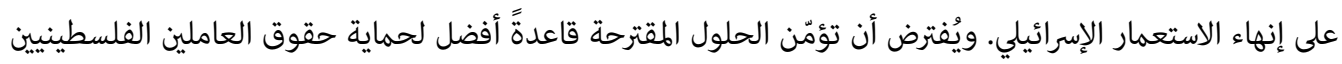

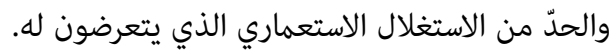




\section{المراجع}

\section{العربية}

"اتفاقية باريس الاقتصادية 1994/4/29". وكالة الأنباء والمعلومات الفلسطينية "وفا". في: http:/bit.ly/3n8pTwh "الإحصــاء الفـلسـيــــي يعلن النتائج الأساسية: مسح القوى العاملة، دورة الربع الرابع 2012 (تشرين أول-كانون أول، 2012)". الجهاز المركزي للإحصاء الفلسطيني. 2013/2/21. في: https:/bit.ly/3bA6wXi "الإحصاء الفلسطيني يعلن النتائج الأساسية لسح القوى العاملة للربع الرابع 2014 (دورة تشرين أول-كانون أول 2014)". الجهاز المركزي للإحصاء الفلسطيني. 2015/2/12. في: https://bit.ly/2WTEq5r "الإحصاء الفلسطيني يعلن النتائج الأساسية لسح القوى العاملة للربع الثاني 2016 (دورة نيسان-حزيران 2016)".

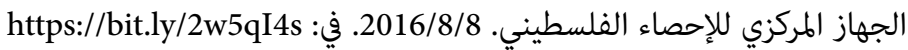
https://bit.ly/33juzYS الأمم المتحدة. الإعلان العالمي لحقوق الإنسان. 1948/12/10. في https://bit.ly/3dq0ISp: الأمم المتحدة. مجلس الأمن. القرار 2334 (2016). 2016/12/23. الجهاز المركزي للإحصاء الفلسطيني. مسح القوى العاملة الفلسطينية: التقرير السنوي 1999. رام الله: 2000. في: https://bit.ly/2RV9deS

https://bit.ly/2wZcsuy مسح القوى العاملة الفلسطينية: التقرير السنوي 2005. رام الله: 2006. في:

https://bit.ly/2VJ0EoC السلوك الخطر للعمال الفلسطينيين في إسرائيل. رام الله: 2010. في:

https://bit.ly/38CZjaj: النتائج الأولية للتعداد العام للسكان والطساكن 2017. رام الله: https://bit.ly/33UmuJv: مسح القوى العاملة الفلسطينية: التقرير السنوي 2018. رام الله: 2019. في

. مسح القوى العاملة: دورة (تشرين أول-كانون أول، 2018)، الربع الرابع 2018. رام الله: 2019. في: https://bit.ly/2xTrEcs https://bit.ly/353pdB4: الحسابات القومية بالأسعار الجارية والثابتة، 2018-2019. رام الله: في . https://bit.ly/3lxG59R مسح القوى العاملة الفلسطينية: التقرير السنوي 2019. رام الله: 2020. في دولة فلسطين. خطة التنمية الوطنية 2014-2016. 23 شباط/ فبراير 2014. في: https:/bit.ly/34fmljP . أجندة السياسات الوطنية 2022-2017: المواطن أولًا. كانون الأول/ ديسمبر 2016. في: https://bit.ly/3bYVcV9 
السلطة الوطنية الفلسطينية، وزارة التخطيط والتنمية الإدارية. خطة التنمية الوطنية 2011-2013: إقامة الدولة وبناء الطستقبل. نيسان/ أبريل 2011. في: https://bit.ly/2X8WBUS

فرسخ، ليلى. العمل الفلسطيني في إسرائيل 1967-1997: مراجعة. رام الله: معهد أبحاث السياسات الاقتصادية الفلسطيني، 1998.

قرار بقانون رقم (4) لسنة 2010م بشأن حظر ومكافحة منتجات المستوطنات. المقتفي: منظومة القضاء والتشريع في فلسطين. 2010/4/26. في: https://bit.ly/3cq1L2Y

قرار بقانون رقم (4) لسنة 2018م بشأن الموازنة العامة لسنة 2018م. المقتفي: منظومة القضاء والتشريع في فلسطين. 2018/3/4. في: https:/bit.ly/3dlTqiO

قرار بقانون رقم (5) لسنة 2011م بشأن الموازنة العامة للسنة الهالية 2011م. المقتفي: منظومة القضاء والتشريع في فلسطين. 2011/3/31. في: https://bit.ly/2GX4GFW

اللجنة الدولية للصليب الأحمر. اتفاقية جنيف الرابعة. 1949/8/12. في: https:/bit.ly/39cyzOM

مركز ماكرو للاقتصاد السياسي. ظروف عمل العاملين بالأجر من الفلسطينيين في إسرائيل. تل أبيب: 2017. في: https://bit.ly/3dNC8Le

المفوضية السامية للأمم المتحدة لحقوق الإنسان. الاتفاقية الدولية للقضاء على جميع أشكال التمييز العنصري.

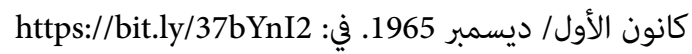

منظمة العمل الدولية. الاتفاقية 169: اتفاقية بشأن الشعوب الأصلية والقبلية في البلدان المستقلة. 1989. في: https://bit.ly/33isQTS

https://bit.ly/34bMvnr الاتفاقية 34: اتفاقية بشأن مكاتب التوظيف بمقابل. 1991. في .

• إعلان منظمة العمل الدولية بشـأن المبادئ والحقوق الأساسية في العمل ومتابعته. مؤتمر العمل الدولي. https://bit.ly/37emExs: الدورة 86. جنيف:

منظمة العمل الدولية. مكتب العمل الدولي. وضع عمال الأراضي العربية المحتلة. مؤتمر العمل الدولي. الدورة 97. تقرير المدير العام (ملحق). جنيف: 2008. في: https://bit.ly/39weTlz

• وضع عمال الأراضي العربية المحتلة. مؤتمر العمل الدولي. الدورة 100. تقرير المدير العام (ملحق). جنيف: 2011. في: https://bit.ly/3bGw1GE

• وضع عمال الأراضي العربية المحتلة. مؤتمر العمل الدولي. الدورة 101. تقرير المدير العام (ملحق). جنيف: 2012. في: https://bit.ly/2yqMvEw 


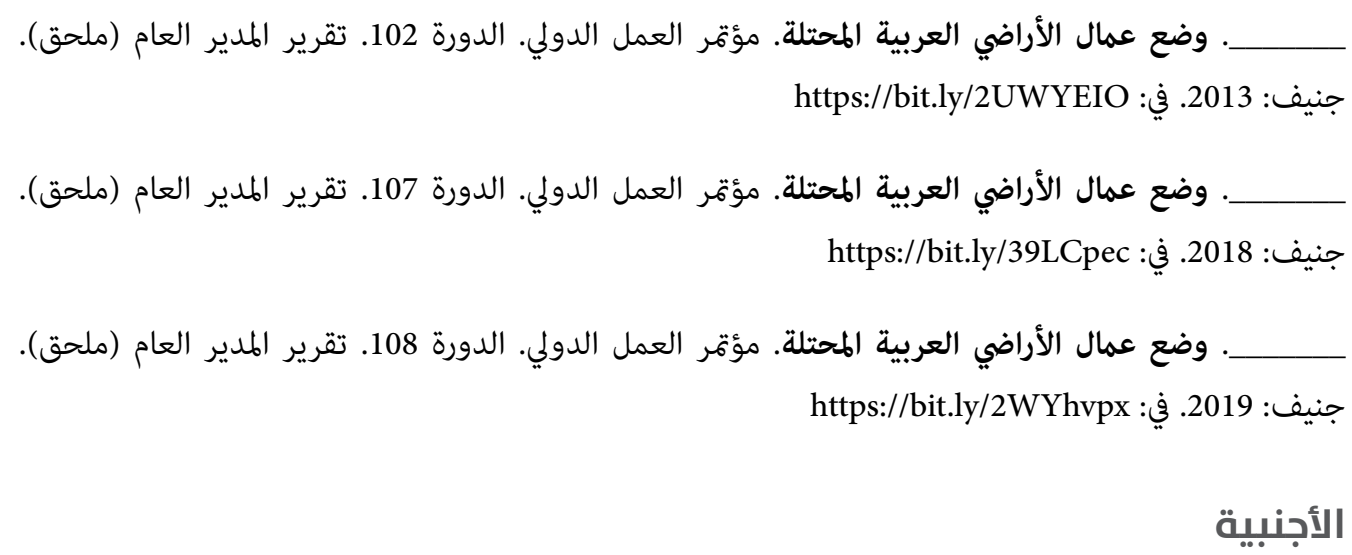

"Illegal Trade in Work Permits for Palestinian Workers in Israel." Bank of Israel. 25/9/2020. at: https://bit.ly/2Xf7S5Q

Office of the United Nations High Commissioner for Human Rights (OHCHR). International Covenant on Economic, Social and Cultural Rights. 16/12/1966. at: https://bit.ly/2J9NDlD

"Palestinian Economy Struggles as Coronavirus Inflicts Losses." The World Bank. 1/6/2020. at: https://bit.ly/3lCa4xj

Phakathi, Timothy Sizwe. "Worker Agency in Colonial, Apartheid and Post-apartheid Gold Mining Workplace Regimes." Review of African Political Economy. vol. 39, no. 132 (2012).

Sayigh, Yusif A. "The Palestinian Economy under Occupation Dependency and Pauperization." Journal of Palestine Studies. vol. 15, no. 4 (Summer 1986).

United Nations. General Assembly. International Convention on the Suppression and Punishment of the Crime of Apartheid. 1974. at: https://bit.ly/2UYoInk 